\title{
Comparative DFT study of triplet and singlet elementary oxidation acts of the cyclohexane and 1,3-cyclohexadiene initiated by primary interaction with ${ }^{3} \mathrm{O}_{2}$ under SCF conditions
}

\author{
(C) Alexandre I. Kourdioukov, ${ }^{1,3} *^{+}$Vener F. Khayrutdinov, ${ }^{2}{ }^{+}$Farid M. Gumerov, ${ }^{2} *$ \\ Asia R. Gabitova, ${ }^{2}$ Anvar A. Ganiev, ${ }^{2}$ Vladimir G. Uryadov, ${ }^{3}$ \\ Evgeny N. Ofitserov, ${ }^{3,4}$ and Aynur F. Mingaliev ${ }^{1,3}$ \\ ${ }^{1}$ Center for New Information Technologies; ${ }^{2}$ Department of Theoretical Foundations of Heat Engineering; \\ Kazan National Research Technological University. K. Marx St., 68. Kazan, 420015. Republic of Tatarstan. \\ Russia. Phone: ${ }^{1)}+7$ (843) 231-42-30; ${ }^{2)}+7$ (843) 231-42-11. \\ ${ }^{3}$ Butlerov Scientific Foundation. Bondarenko St., 33-44. Kazan, 420066. Republic of Tatarstan. Russia. \\ E-mail: butlerov@mail.ru;vguryadov@mail.ru \\ ${ }^{4}$ Department of Chemistry and Technology of Biomedical Preparations. Faculty of Chemical Pharmaceutical \\ Technologies and Biomedical Preparations. D.I. Mendeleev Russian University of Chemical Technology. \\ Miusskaya Sq., 9. Moscow, 125047.Russia.Phone:+7 (495)978-32-61.E-mail:ofitser@mail.ru
}

*Supervising author; ${ }^{+}$Corresponding author

Keywords: alkanes, cycloalkanes, molecular oxygen, oxygen-induced $\mathrm{C}-\mathrm{H}$ bond cleavage, triplet hydrogen complexes, oxidative dehydrogenation, organic hydroperoxides, reaction mechanisms, elementary events, DFT method.

\section{Abstract}

The primary stages of the oxidation of model cyclohexane and 1,3-cyclohexadiene by triplet molecular oxygen and subsequent transformations involving triplet and singlet states were studied for the first time by the DFT method with the density functional B3LYP with the basis set $6-311++\mathrm{g}(\mathrm{df}, \mathrm{p})$.

It was shown that, ceteris paribus, cyclohexane and 1,3-cyclohexadiene will be orders of magnitude more reactive compared to the activity of acyclic saturated hydrocarbons under GFR conditions when the oxidation process is initiated by the primary reaction with ${ }^{3} \mathrm{O}_{2}$, which allows the propane-butane mixture to be effectively used as SCF conditions of heavy oils and use air purge to activate this process.

The triplet associate complexes resulting from the oxidative cleavage of the secondary $\mathrm{C}-\mathrm{H}$ bond of cyclohexane and 1,3-cyclohexadiene consist of hydrogen-bonded hydroperoxyl radical and cyclohexyl radical or 1,3-cyclohexadiene radical, respectively. These complexes can dissociate into unbound pairs of radicals, and therefore further reactions can proceed in the triplet or singlet direction.

The singlet direction is characterized by hydrate-induced hydroperoxide-carbonyl transformation, as well as other hydrate-induced rearrangements.

The triplet direction is characterized by the occurrence of triplet rearrangement, which in its essence is a triplet recombination of associated radicals.

Associate triplet complexes can be agents of radical hydroperoxyl and alkyl activity, as well as agents of radical hydroxyl and alkoxyl activity.

Most oxidative dehydrogenation reactions are absolutely real under a number of conditions, namely, they must take place under GFR conditions, as well as in the presence of an excess of SCF solvent necessary for the effective shift of thermodynamic equilibrium towards the target products in accordance with the Le Chatelier principle.

\section{References}

[1] A.I. Kourdioukov, Vener F. Khayrutdinov, F.M. Gumerov, A.R. Gabitova, V.G. Uryadov, A.F. Mingaliev, and E.N. Ofitserov. Triplet oxygen-water associates as the main agents of acidifying autocatalytic redoxprocesses. Quantum-chemical description of primary elementary acts of combustion. Butlerov Communications. 2017. Vol.52. No.10. P.17-27. DOI: 10.37952/ROI-jbc-01/17-52-10-17

[2] N.E. Damoyi, H.B. Friedrich, H.G. Kruger, D. Willock. Density Functional Theory Studies of the Uncatalysed Gas-Phase Oxidative Dehydrogenation Conversion of n-Hexane to Hexenes. Computational and Theoretical Chemistry. 2017. Vol.1114. P.153-164. 
COMPARATIVE DFT STUDY OF TRIPLET AND SINGLET ELEMENTARY OXIDATION ACTS...

[3] A.I. Kourdioukov, Vener F. Khayrutdinov, F.M. Gumerov, A.R. Gabitova, I.Z. Salikhov, V.G. Uryadov, E.N. Ofitserov, A.F. Mingaliev, and A.V. Trofimov. DFT study of triplet and singlet elementary acts of acyclic and cyclic alkanes oxidation initiated by primary interaction with ${ }^{3} \mathrm{O}_{2}$. Butlerov Communications. 2019. Vol.60. No.11. P.114-127. DOI: 10.37952/ROI-jbc-01/19-60-11-114

[4] V.F. Khairutdinov, A.R. Gabitova, F.M. Gumerov, R.F. Gabitov, A.I. Kourdioukov. Extraction of oil products and resin-asphaltene mixtures from highly watered oil sludge by supercritical fluid extraction. Supercritical Fluids: Theory and Practice. 2018. Vol.13. No.3. P.97-102. (Russian); F.M. Gumerov, V.F. Khairutdinov, T.R.

Akhmetzyanov, F.R. Gabitov, Z.I. Zaripov, M.I. Farakhov, A.V. Mukhutdinov. Supercritical fluid propane-butane extraction treatment of oil sludge. Supercritical Fluids: Theory and Practice. 2016. Vol.11. No.2. P.75-83.

(Russian); F.M. Gumerov, M.I. Farakhov, V.F. Khairutdinov. Oil sludge utilization technology using liquid and supercritical fluid extraction with propane-butane extractant. Theoretical foundations of chemical technology. 2017. Vol.51. No.6. P.629-636. (Russian)

[5] A.I. Rakhimov. Chemistry and technology of organic peroxide compounds. 1979. Moscow: Chemistry. 392p. (Russian)

[6] I.V. Berezin, E.T. Denisov, N.M. Emanuel. Oxidation of cyclohexane. 1962. Moscow: Publishing house of Moscow University. 302p. (Russian)

[7] A.I. Kourdioukov, A.R. Gabitova, F.M. Gumerov, E.N. Ofitserov, and D.L. Egorov. Quantum-chemical study of the transformation of triglycerides. Part 4. Elementary acts of supercritical water oxidation (SCWO) model analogs fatty acid triglycerides in supercritical fluid media. Butlerov Communications. 2015. Vol.44. No.10. P.153-197. DOI: $10.37952 /$ ROI-jbc-01/15-44-10-153 